\title{
Exploring the Preferred Learning Style of Preservice Teachers and How This Influences Their Philosophy of Teaching
}

\author{
H. Young ${ }^{1}$, B. Coleman ${ }^{2}$, C. Jagger ${ }^{3}$, P. Sweet Moore ${ }^{4}$, J.C. Bunch ${ }^{5}$
}

\begin{abstract}
The purpose of this mixed methods study was to address how preservice teachers' preferred learning style influences their philosophy of teaching agricultural education. A convergent parallel mixed methods design was used in which quantitative and qualitative data were collected simultaneously, analyzed separately, and then merged for combined analysis. In this study, we identified 17 preservice teachers' learning style and then assessed how their learning style influenced their philosophy statement. We found $59 \%$ of the teaching philosophy statements were similar to the preservice teachers' learning style, $18 \%$ were different, and $23 \%$ were deemed inconclusive. It appears the preferred learning style of preservice teachers does carry through into their teaching philosophy. The percentage of inconclusive statements show that teachers will incorporate multiple learning styles to meet the diverse learning needs of their students. When the various learning styles of a class are met, it is suggested that the learning experience will be more effective and beneficial for the learners. Based on the findings of this study, we recommend implementing professional development sessions to help teachers blend their preferred learning style with the needs of their learners. Additionally, further research is needed to compare teachers' actual practice with their teaching philosophies.
\end{abstract}

\section{Keywords}

Teaching philosophies, agricultural education, Kolb LSI, mixed methods

1. Heather L. Young, Graduate Assistant, University of Florida, 310 Rolfs Hall. PO Box 110540, Gainesville. FL 32611, heather.young@ufl.edu, (D.Dhttps://orcid.org/0000-0003-2236-5054

2. Bradley M. Coleman, Graduate Assistant, University of Florida, 310 Rolfs Hall, PO Box 110540, Gainesville, FL 32611, bradleycoleman@ufl.edu,_ i https://orcid.org/0000-0001-5981-5747

3. Carla B. Jagger, Assistant Professor, University of Florida, 307B Rolfs Hall, PO Box 110540, Gainesville, FL 32611, carlajagger@ufl.edu, ID https://orcid.org/0000-0001-9796-6271

4. Peyton E. Sweet Moore, Graduate Student, University of Florida, 408 Rolfs Hall, PO Box 110540, Gainesville, FL 32611, psweetmoore@ufl.edu, (D https://orcid.org/0000-0002-9974-1698

5. J. C. Bunch, Associate Professor, University of Florida, 307A Rolfs Hall, PO Box 110540, Gainesville, FL 32611, bunchj@ufl.edu, ID https://orcid.org/0000-0001-8729-2349 


\section{Introduction and Problem Statement}

Novice middle and high school teachers often teach how they were taught or how the individual teacher prefers to learn (Brown, 2003). However, the way teachers were taught may often times be different than the learning preferences found in a classroom of diverse learners. Recognizing students learn in different ways, middle and high school teachers have adjusted their pedagogical approaches by using multiple teaching methods to help meet the needs of their diverse learners (Brown, 2003; Delahoussaye, 2002; Heimlich \& Norland, 2002; Hernandez et al., 2020; Hydrie \& Naqvi, 2021; Kolb \& Kolb, 2006; Loewenberg Ball \& Forzani, 2009; Miller, 2001; Seaman \& Fellenz, 1990). Typically, novice teachers have developed a teaching philosophy as part of their teacher preparation program to assist novice teachers in guiding their practice (Caukin \& Brinthaupt, 2017).

Schönwetter et al. (2002) purported that an effective teaching philosophy statement includes characteristics of one's teaching strategies, rationale for teaching, guiding teaching behaviors, organizing evaluation of teaching, promoting personal and professional development, and encouraging the sharing of effective teaching. A teaching philosophy should specifically state one's definition of teaching, definition of learning, the view of the learner, the goals and expectations of the student - teacher relationship, a discussion of teaching methods, as well as a discussion of evaluation (Schönwetter et al., 2002). Literature supports the idea of novice teachers teaching how they were taught (Beegle \& Coffee, 1991; Oleson \& Hora, 2014). Further, positive results are achieved when agriscience students are taught using their preferred learning style (Baker \& Robinson, 2019; Smith \& Rayfield, 2019). Therefore, there is a need to investigate how preservice teachers' learning styles influence their initial teaching philosophies, which could influence their pedagogical preferences as a novice teacher.

\section{Theoretical and Conceptual Framework}

The conceptual framework used for this study was Kolb's (2017) Learning Style Inventory (LSI). The LSI is founded upon the principles of Kolb's (1984) model of experiential learning. Kolb (2017) revised the LSI to include nine different learning styles instead of the original four, including, initiating, experiencing, imagining, reflecting, analyzing, thinking, deciding, acting, and balancing.

The initiating learning style is identified by initiating action to deal with varying experiences and situations. Experiencing learning style is identified by finding meaning from being deeply involved in experiences. Individuals with an imagining learning style can imagine the possibilities based on what they have observed and reflected upon. They are aware of people's feelings and values by listening and having an open mind. Someone with a reflecting learning style understands others' point of view and can grasp what is happening in a situation, while being able to explain it in detail. Individuals with an analyzing learning style are seen as logical and typically excel in organizing varying information in a concise form, creating conceptual models, and rational thinking (Kolb, 2017). 
The thinking learning style is identified by the ability for logical reasoning and rational decision making, as well as strong data analysis skills. Goal setting, decision making, problem-solving, and evaluating solutions are all strengths of those with a deciding learning style. The acting learning style is described as a combination of technical knowledge, personal relationships, and getting projects completed. Individuals with the acting learning style are focused on setting goals to help them get tasks accomplished by testing their ideas with experiences in the area and concepts they have created to complete the task. Balancing learning style individuals typically have the ability to be flexible and work well within diverse groups. Since they do well with balancing between all types of learning, they are often seen as being indecisive and having their 'hands in too many pots', where they are not able to focus on the topic at hand (Kolb, 2017).

\section{Purpose}

The purpose of this mixed methods study was to address how preservice teachers' preferred learning style influences their philosophy of teaching agricultural education. A convergent parallel mixed methods design was used in which quantitative and qualitative data were collected simultaneously, analyzed separately, and then merged for combined analysis (Creswell \& Plano Clark, 2018). Descriptive, quantitative data were used to describe the preservice teachers' preferred learning style category. Qualitative data, in the form of preservice teachers' teaching philosophy statements, were used in comparison with their preferred learning style. The data were then merged in a data matrix and analyzed to address the following research questions:

1. What are the preservice teachers' preferred learning styles as defined by the Kolb LSI instrument?

2. How do preservice teachers' preferred learning style influence their teaching philosophy statements?

\section{Methods}

A convergent parallel mixed method design was used (Creswell \& Plano Clark, 2018). All data were collected from preservice teachers enrolled in, AEC 4224: Special Methods in Teaching Agricultural Education, which is the student teaching preparation block course in the Department of Agricultural Education and Communication at the University of Florida. The first strand of data was quantitative and measured the preservice teachers' preferred learning style. The qualitative strand of data included the preservice teachers' teaching philosophy statements. In total, nineteen teaching philosophy statements $(N=19)$ were submitted, however, only 17 philosophies ( $n=17$ ) were analyzed due to incomplete data. Participant demographics included 16 females and one male. There were 16 preservice teachers who identified as White, and one preservice teacher identified as Hispanic.

Researchers' biases and perspectives are potentially influential of the research process and should be addressed to help in reducing bias (Patton, 2002). Of the five researchers, two are 
university agricultural teacher education faculty. One faculty member currently serves as the teacher certification program coordinator and the lead instructor of the student teacher preparation block course. Three of the researchers are graduate students in agricultural education. Weekly meetings were held among the authorship team to reduce bias and share perspectives.

\section{Data Collection and Instrumentation}

Each preservice teacher completed Kolb's LSI questionnaire. This instrument consists of 12items which describe learning situations where participants rank themselves from one to four, with 1 = least like you and $4=$ most like you. In addition to the LSI, preservice teachers were asked to compose their teaching philosophies based on the following questions: (a) What do you teach? (b) Why do you teach? (c) How do you view your students? (d) How do you teach? (e) How do you know if you have been successful?

\section{Data Analysis}

For the quantitative strand of data, preservice teachers' LSI scores were calculated following the LSI grid design to establish their score and learning style. To analyze the qualitative data strand, each philosophy statement was analyzed deductively for congruent and discrepant statements according to their calculated learning style. For example, a philosophy statement from a preservice teacher with an initiating learning style was analyzed, keeping those characteristics in mind, to determine if their philosophy statement reflected that learning style. Congruent statements were those closely related to the learning style characteristics, as described in the LSI workbook (Kolb, 2017). Additionally, LSI scores that reflected one learning style and a philosophy statement that reflected another learning style in the same quadrant were considered similar and analyzed as congruent. Discrepant statements were identified as being related to any other learning style outside of the participant's learning style quadrant on the LSI scoring grid. In other words, if their LSI score fell in the top left quadrant (initiating) but had mostly statements clearly reflecting a learning style from another quadrant (e.g., imaging, reflecting, analyzing, thinking, deciding) they were analyzed as discrepant. Finally, if $50 \%$ or more of the philosophy statement did not align with a specific learning style, it was considered an inconclusive case.

While analyzing the philosophy statements each participant's learning style was recorded at the top of their work and annotated notes were recorded throughout to identify congruent or discrepant statements to specific learning styles. Additionally, each philosophy statement was reanalyzed multiple times to validate the annotated analysis. These steps helped to establish the validity of the reported findings. Finally, the results of the two strands of data were integrated through the comparison of data across learning style groups (Creswell \& Plano Clark, 2018; Bazeley, 2009). This integration was situated into a data matrix which featured the quantitative results and a summary of qualitative findings. 


\section{Findings}

Research Question One: What are the preservice teachers' preferred learning styles as defined by the Kolb LSI instrument?

Descriptive statistics were calculated to describe the learning styles of each preservice teacher based on the Kolb LSI instrument. Within the sample $(n=17), 41.2 \%$ ( $f=7)$ of the preservice teachers had an acting learning style, $29.4 \%(f=5)$ had an initiating learning style, $11.8 \%(f=2)$ had a balancing learning style, 5.9\% $(f=1)$ had an experiencing learning style, $5.9 \%(f=1)$ had a reflecting learning style, and $5.9 \%(f=1)$ had a thinking learning style. There were no imagining, deciding, or analyzing learning styles among the preservice teachers. The individual participants' learning styles are reported in Table 1.

\section{Table 1}

Summary of Participants' Individual Kolb LSI Learning Styles

\begin{tabular}{ll}
\hline Kolb Learning Style & Participant \\
\hline Acting & Teacher 1, Teacher 2, Teacher 5, Teacher 7, Teacher 8, Teacher 9, \\
& Teacher 15 \\
Initiating & Teacher 3, Teacher 4, Teacher 10, Teacher 13, Teacher 16 \\
Balancing & Teacher 14, Teacher 17 \\
Reflecting & Teacher 6 \\
Thinking & Teacher 11 \\
Experiencing & Teacher 12 \\
\hline
\end{tabular}

Research Question Two: How do preservice teachers' preferred learning style influence their teaching philosophy statements?

Qualitative data were collected on the preservice teachers' philosophy statements and were analyzed based on the preservice teachers' developed teaching philosophy statement. The objective was to determine whether or not the personal learning style of the preservice teachers had an influence on their teaching philosophy statements. There were ten teachers ( 1 , $2,6,8,9,10,12,13,15,17)$ who were congruent regarding their philosophy statements and their LSI scores. Three teachers $(7,14,16)$ had discrepant statements within their philosophy statement compared to their LSI scores. There were four preservice teachers $(3,4,5,11)$ who had multiple learning styles present in their teaching philosophy statement and were reported as inconclusive.

\section{Acting}

The most frequently occurring learning style within the teaching philosophies was the acting learning style. Acting learners do well with combining tasks, teammate needs, and addressing questions and problems, while still being personable and responsible. They learn best when they are involved in conversations with co-workers and within teams. Acting learners prefer to 
work with a teacher who has practical real-life experience students can learn from. Teachers 1 , $2,8,9,14$, and 15 were identified as acting style based upon their teaching statements. All of these teachers, except for 14, had statements which aligned with their LSI scores, as acting, while teacher 14 was discrepant to their LSI score of balancing.

Participants within this learning style had the following congruent statements within their philosophies, "A quality SAE is one where students go beyond the classroom and take their learning into their own hands and into the real world...to develop their own interests so the skills they acquire may be useful" (Teacher 9). Teacher 15 believes "the [students'] responsibilities are to understand and demonstrate their knowledge of all subjects...in an agriculture-based classroom... The student should engage in classroom activities and discussions...learning how to apply the things they've learned in class." Teacher 8 similarly mentioned "I will provide them knowledge for specified courses, which they will be able to apply in real life scenarios. Students will be advised to [participate] in a supervised agriculture experience (SAE) of their interest."

\section{Initiating}

The next learning style from the teaching philosophies was the initiating learning style, which teachers 10 and 13 were identified as and were congruent with their LSI score. Characteristics of this learning style are preferring a hands-on, real-life learning situation; willingness to try out new and challenging experiences; volunteering for leadership positions; starting new projects, taking risks, identifying new strategies for completion; learners often act on 'gut' feelings, spontaneity, energetic, persuasion, and courage. Initiating learners usually excel in learning environments where they can work together in groups to try out different ways to complete the assignment. Teacher 10 presents the desire to serve as a mentor to students by "leading by example and [using] my agricultural experiences to guide and direct them. I will make it a priority to help students find their passion through supervised agriculture experiences." Teacher 13 "strongly believes in the educational power of immersing children into the realworld application of the lesson at hand."

\section{Reflecting}

The third learning style, which included teacher 6 and 7; 6 being congruent with reflecting and 7 being discrepant of their LSI score of acting, was the reflecting learning style. These preservice teachers connect experiences and ideas through sustained reflection. Reflective learners are able to organize information in a way to aid reflection. They enjoy being able to come up with various solutions or approaches to a problem and offering detailed insight. Since reflective learners are quiet, sensitive, and thorough, interjecting in a group conversation or being the one to take action is often difficult for them.

A couple congruent statements include, "I know [I have accomplished my purpose] if they walk out of my classroom knowing more than they did before and fostering a passion for the agricultural industry" (Teacher 7). Teacher 6 stated "teaching styles have a great impact on the audience you are trying to reach. I will teach to accommodate different learning styles to the best of my ability." 


\section{Experiencing}

The fourth learning style was experiencing. Teacher 12's philosophy statement similarly identified with the experiencing learning style. Experiencing learners will feed off constructive feedback in both their professional and personal lives, as well as desiring to build personal relationships with their teachers. They enjoy working in groups but need time to work alone to finalize a project; they prefer learning by meaningful interactions and continuing conversations with friends and co-workers; they are open minded, accepting, helpful, empathetic, sensitive to others' feelings, innovative, and take unique approaches to problem solving. This particular preservice teacher found meaning from deep involvement in experiences. "I incorporate exploration and hands-on learning. I listen to the desires of students while meeting it with the expectations of the world they are going into."

\section{Balancing}

The fifth learning style was the balancing learning style, in which teacher 17's philosophy statement identified with and was aligned to their LSI score. This preservice teacher adapted by weighing the pros and cons of acting versus reflecting and experiencing versus thinking. "Each student is unique and has their own experiences that will inspire them to make a change...I teach my students while they are in groups so that they can learn to communicate and help one another." In reference to individuals with a balancing learning style, they can easily change from thinking to feeling and reflecting to acting, all depending on the situation, allowing them to fill in the missing learning style within the team. Considering their ability to adapt and fit whatever style is needed, they often switch careers due to their changing interests, consequently leading them in a different direction.

\section{Imagining}

The sixth learning style was the imagining learning style, which included teacher 16 who was discrepant from their LSI score of initiating. Observing and reflecting on experiences and individual's feelings aid in their learning, as well as allowing them to connect differences within the group. They are open to different thoughts and opinions due to their ability to look at things with multiple points of view. Observation leads action with this learning style which allows learners to think through cause-and-effect situations for a certain action and helps to create alternative solutions to the problem. This preservice teacher discussed imagining the possibilities by observing and reflecting on experiences. "I believe it is my job to learn about my students and try to understand them."

\section{Inconclusive}

Teachers 3, 4, 5, and 11 had philosophy statements which aligned with multiple learning styles and did not fully connect back to their identified learning style. Teachers 3 and 4 had LSI scores that were initiating, teacher 5 had an LSI score that was acting, and teacher 11 had an LSI score of thinking. These preservice teachers' philosophy statements did not specifically fit into one particular learning style. Examples from these teachers' philosophy statements are presented in Table 2 under both the congruent and discrepant columns highlighting several quotes from each preservice teacher representing multiple learning styles. 


\section{Table 2}

Comparing Teaching Philosophy Statements of Preservice Teachers and Their Preferred Learning Styles

Congruent Statements Discrepant Statements

Acting Style. A strong motivation for goal directed action that integrates people and tasks $(f=7$ Teachers)

"I will have...surveys at the beginning and end of the year...students write down what they wish to accomplish during the class and then follow with what they believe should be improved in the program at the end of the class" (Teacher 1$)$.

“...you cannot learn everything from a PowerPoint and lecture, a lot of things in agriculture needs to be experienced by the student in order for them to fully understand how things work" (Teacher 2).

"My agriculture program stems from the idea of creating skilled, agriculturally literate people who will be lifelong learners" (Teacher 8).

"I believe that using group projects, discussions, and debate in my classroom allows students to build interpersonal skills and learn from each other" (Teacher 9).

"My students will be taught how to speak in front of others... [and] dress professionally. There is no specific class to give students simple lessons for necessary parts of life, such as job interview skills" (Teacher 15).

Initiating Style. Initiating action to deal with experiences and situations ( $f=5$ Teachers)

“...technology should not replace the physical experience that students receive in a land lab. Students will have the opportunity to get their hands dirty and follow the FFA motto by 'Doing to Learn" (Teacher 4).
"I plan to rely on various teaching methods to ensure I equip each student with the materials needed for achievement" (Teacher $5)$.

“...benefits of blending various teaching methods throughout a lesson is vital for learning and retaining the information" (Teacher 5).

"Learning is the first requirement, but most important is retaining and that is the true necessity for success. Being open about receiving feedback is essential, I value my students' opinion and appreciate their honest criticisms" (Teacher 5).

"My students reflect myself and my teaching. If I do my job well...students will be knowledgeable, informed, and able to go into the world confidently; sharing the knowledge they have gained through my teaching" (Teacher 7). 
"My teaching style is unique to itself in that it reflects not only how I learn but also how I was previously taught. A combination of lectures, labs, practicums, and group and independent work will be included in my teaching. I believe students learn best when they are presented content in a variety of ways" (Teacher 10).

"Hands-on and investigative learning techniques will be utilized to encourage students to explore and discover new concepts on their own" (Teacher 13). "...my students are a team; I see the value and determination in the individuals that I am helping them become" (Teacher 3).

"I encourage constructive criticism and feedback because I owe it to my students to be the teacher they deserve" (Teacher 3 ).

“...Important to chart student progress as they move through the program...tested on information before, during, and after... success can be viewed in the land lab as they will apply what they learn in class" (Teacher 4).

"I will ask for honest feedback and make sure all students that wish to speak, have a chance to do so...students should be encouraged to be their true authentic self, it is our difference that brings us together" (Teacher 4).

"I am always working on bettering myself, to better serve my students. I constantly look to improve myself...through reflection and professional development" (Teacher 16).

Balancing Style. Adapting by weighing the pros and cons of acting versus reflecting, and experiencing versus thinking $(f=2$ Teachers)

"I teach agriculture...[but]...I also teach life "My goal as an agriculture teacher is to teach lessons [to] help prepare and guide my students any course needed in the community or for their future...I teach beneficial skills such as desired by students, to prepare them for the communication, leadership, public speaking, [future]. My objective is to produce record management, how to work together, knowledgeable, skilled, lifelong learners who and help others" (Teacher 17). are inspired to continue ag ed" (Teacher 14).

\section{Experiencing Style. Finding meaning from deep involvement in experience}

( $f=1$ Teacher)

"I teach to inspire...to be passionate...I teach because these were all things my teacher taught me, and I don't want students to go through the entire school system without knowing what it's like to have someone rooting for you" (Teacher 12). 
Reflecting Style. Connecting experience and ideas through sustained reflection

$(f=1$ Teacher $)$

"Group style learning encompassing "Think-

Pair-Share" techniques will be used to allow

students the ability to connect their ideas with

others" (Teacher 6).

"I will record [my] lectures and observe these to find areas of improvement and will openly ask for the other educators' observations...attend [professional development] to meet [student] needs ..." (Teacher 6).

Thinking Style. Disciplined involvement in abstract reasoning and logical reasoning ( $f=1$ Teacher $)$

"I vow as a teacher to always be respectful and " prepared for class. I hope that I am seen as a resource to students not only in the classroom, but in real-life setting" (Teacher 11).

"I count myself as successful if students exit the program as informed, skilled, productive citizens...program's growth can be measured through certification exams, student feedback, community support, student career choices" (Teacher 11).
“Much of an agriculture program's best resources are found outside of the classroom...Farmers, agribusinessmen, grocery store managers, florists, and others all have skills that can showcase the career opportunities in agriculture" (Teacher 11).

"Auditory, kinesthetic, visual learners will find project-based assignments engaging and applicable to life" (Teacher 11).

\section{Conclusions, Discussion, and Recommendations}

The purpose of this study was to determine if a preservice teachers' learning style transfers to their teaching philosophy statement. The first aim of the study was to identify preservice teachers' learning styles through Kolb's (2017) LSI. The majority $(n=12)$ of preservice teachers identified with the acting or initiating learning styles. Appearing side-by-side on the LSI grid and connecting strongly to active experimentation and concrete experiences within experiential learning, these learners are focused on creating a plan and implementing it. As described by Kolb (2017), both of these learning styles have strong connections to real-world and hands-on experiences, which tend to be key teaching approaches within agricultural education. Additionally, five of the preservice teachers were split across the balancing $(n=2)$, thinking $(n=$ $1)$, reflecting $(n=1)$, and experiencing $(n=1)$ learning styles, all of which appear across the central axis of the LSI grid, representing how learners work from determining what is a problem and how they can carry out the solution for that problem. Imagining, deciding, and analyzing 
learning styles were not among the learning styles with which this group of preservice teachers identified. Each of these learning styles fall in three of the four corners on the LSI grid, which would require an individual to have strong preferences towards characteristics of that style, such as choosing a solution, recognizing problems with that solution, and considering any alternative solutions.

The second part of the study was to analyze the preservice teachers' philosophy statements and deductively align data to their calculated learning style, as defined by their LSI score. Ten (59\%) preservice teachers' teaching philosophies appeared to align with their assigned style from the LSI. It should be noted, while analyzing preservice teachers' philosophy statements from the acting and initiating styles, if there were elements that resembled the inclusion of real-world applications, they were coded as being congruent to their respective learning style since these two styles are so closely related. From this trend, it appears that the preferred learning style does translate into their teaching philosophy potentially linking back to the way they were taught (Beegle \& Coffee, 1991; Oleson \& Hora, 2014). Additionally, three (18\%) philosophies were different from the teachers preferred learning styles and there were four (23\%) philosophies which were deemed inconclusive when compared to their preferred learning style. These differences from the teachers' preferred learning style aligns more with the notion by Sankey and Foster (2012) and Kolb (1984) that teachers often incorporate multiple learning styles to match the diverse learning preferences of their students. Since the inconclusive philosophy statements reflect multiple learning styles, this could be an indicator that teachers may incorporate multiple learning styles within classroom instruction (Brown, 2003; Delahoussaye, 2002; Heimlich \& Norland, 2002; Hernandez et al., 2020; Hydrie \& Naqvi, 2021; Kolb \& Kolb, 2006; Loewenberg Ball \& Forzani, 2009; Miller, 2001; Seaman \& Fellenz, 1990).

Based on these findings it could be beneficial for teacher educators to implement class sessions in their teacher preparation courses to help preservice teachers add to their teacher toolbox, while learning how to blend their preferred learning style with the diverse learning needs of their students, to allow for an effective educational environment. The researchers recognize these findings only apply to this specific population. Therefore, further research should be conducted regarding how learning styles transfer to teaching philosophy statements and to actual teaching behaviors. For example, observations of participating teachers could be conducted to determine if their philosophy statements and LSI scores translate to their actual teaching practices. Additionally, teachers could be tracked over time for longitudinal analysis of their teaching style compared to their philosophy statements.

\section{References}

Baker, M. A., \& Robinson, J. S. (2019). The interaction of learning style on measures of successful intelligence in secondary agriculture students exposed to experiential and direct instruction. Journal of Agricultural Education, 60(3), 14-31. https://doi.org/10.5032/jae.2019.03014 
Bazeley, P. (2009). Editorial: Integrating data analyses in mixed methods research. Journal of Mixed Methods Research, 3(3), 203-207. https://doi.org/10.1177/1558689809334443

Beegle, J., \& Coffee, D. (1991). Accounting instructors' perceptions of how they teach versus how they were taught. Journal of Education for Business, 67(2), 90-94. https://doi.org/10.1080/08832323.1991.10117524

Brown, B. L. (2003). Teaching style vs. learning style. Myths and realities. ERIC Publications. https://eric.ed.gov/?id=ED482329

Caukin, N. G., \& Brinthaupt, T. M. (2017). Using a teaching philosophy statement as a professional development tool for teacher candidates. International Journal for the Scholarship of Teaching and Learning, (11)2, 1-9. https://doi.org/10.20429/ijsotl.2017.110218

Creswell, J. W., \& Plano Clark, V. L. (2018). Designing and conducting mixed methods research (3rd ed.). SAGE.

Delahoussaye, M. (2002). The perfect learner: An expert debate on learning styles. Training, 39(5), 28-36.

Heimlich, J. E., \& Norland, E. (2002). Teaching style: Where are we now? New Directions for Adults and Continuing Education, 2002(93), 17-25. https://doi.org/10.1002/ace.46

Hernandez, J. E., Vasan, N., Huff, S., \& Melovitz-Vasan, C. (2020). Learning styles preferences among medical students: Kinesthetic learner's multimodal approach to learning anatomy. Medical Science Educator, 30, 1633-1638. https://doi.org/10.1007/s40670$\underline{020-01049-1}$

Hydrie, M. Z. I., \& Naqvi, S. M. Z. H. (2021). Assessing learning styles of medical students using Kolb's learning style inventory and their association with preferred teaching methodologies. Journal of the Pakistan Medical Association, 71(4), 1157-1161. https://www.jpma.org.pk/article-details/10601

Kolb, D. A. (1984). Experiential learning: Experience as the source of learning and development. Prentice Hall.

Kolb, D. A. (2017). Kolb learning style inventory: Workbook version 3.2. Korn Ferry Hay Group.

Kolb, A. Y., \& Kolb, D. A. (2006). Learning styles and learning spaces: A review of the multidisciplinary application of experiential learning theory in higher education. Nova Science Publishers, Inc. https://www.researchgate.net/publication/291046218 
Loewenberg Ball, D., \& Forzani, F. M. (2009). The work of teaching and the challenge for teacher education. Journal of Teacher Education, 60(5), 497-511. https://doi.org/10.1177/0022487109348479

Miller, P. (2001). Learning styles: The multimedia of the mind (ED451340). ERIC. https://files.eric.ed.gov/fulltext/ED451140.pdf

Oleson, A., \& Hora, M. T. (2014). Teaching the way they were taught? Revisiting the sources of teaching knowledge and the role of prior experience in shaping faculty teaching practices. Higher Education, 68, 29-45. https://doi.org/10.1007/s10734-013-9678-9

Patton, M. Q. (2002). Qualitative research and evaluation methods (3rd ed.). SAGE.

Sankey, L. L., \& Foster, D. D. (2012). A content analysis of teaching philosophy statements of award-winning colleges of agriculture professors. Journal of Agricultural Education, 53(4), 124-140. https://doi.org/10.5032/jae.2012.04124

Schönwetter, D. J., Sokal, L., Friesen, M., \& Taylor, K. L. (2002). Teaching philosophies reconsidered: A conceptual model for the development and evaluation of teaching philosophy statements. The International Journal for Academic Development, 7(1), 8397. https://doi.org/10.1080/13601440210156501

Seaman, D. F., \& Fellenz, R. A. (1990). Effective strategies for teaching adults. Merrill.

Smith, K. L., \& Rayfield, J. (2019). STEM knowledge, learning disabilities and experiential learning: Influences of sequencing instruction. Journal of Agricultural Education, 60(2), 222-236. https://doi.org/10.5032/jae.2019.02222

(C) 2021 by authors. This article is an open access article distributed under the terms and conditions of the Creative Commons Attribution license (http://creativecommons.org/licenses/by/4.0/). 